\title{
Corrigendum: Allopregnanolone, the Neuromodulator Turned Therapeutic Agent: Thank You, Next?
}

\author{
Graziano Pinna* \\ Department of Psychiatry, The Psychiatric Institute, University of Illinois at Chicago, Chicago, IL, United States
}

Keywords: brexanolone, allopregnanolone $(3 \alpha, 5 \alpha-\mathrm{THP})$, postpartum depression, fast-acting antidepressant, $\mathrm{GABA}_{\mathrm{A}}$ receptor, $5 \alpha$-reduced steroids, $5 \alpha$-reductase, $3 \alpha$-HSD

\section{OPEN ACCESS}

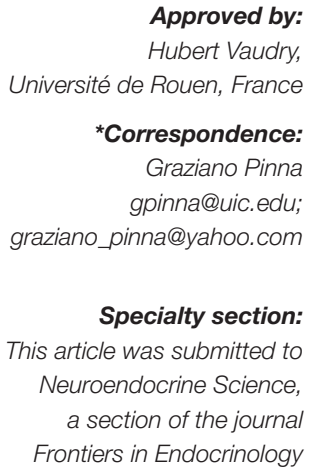

Approved by:

Hubert Vaudry,

Université de Rouen, France

*Correspondence:

Graziano Pinna

gpinna@uic.edu;

graziano_pinna@yahoo.com

Specialty section:

This article was submitted to Neuroendocrine Science,

a section of the journal

Frontiers in Endocrinology

Received: 11 June 2020

Accepted: 24 June 2020

Published: 30 July 2020

Citation:

Pinna G (2020) Corrigendum:

Allopregnanolone, the

Neuromodulator Turned Therapeutic

Agent: Thank You, Next?

Front. Endocrinol. 11:507.

doi: 10.3389/fendo.2020.00507

\section{A Corrigendum on}

Allopregnanolone, the Neuromodulator Turned Therapeutic Agent: Thank You, Next? by Pinna, G. (2020). Front. Endocrinol. 11:236. doi: 10.3389/fendo.2020.00236

In the original article, there was an error. "Allopregnanolone, today best known as brexanolone and marketed as Zulresso ${ }^{\mathrm{TM}}$ for the treatment of postpartum depression is part of only two recently Food and Drug Administration (FDA)-approved fast-acting antidepressants, with esketamine nasal spray, an NMDA receptor antagonist used in treatment-resistant depression with suicidality being the other." However, SPRAVATO ${ }^{\circledR}$ (esketamine) CIII Nasal Spray was approved by the FDA last year to treat treatment-resistant depression in adults when used along with an oral antidepressant, and is not indicated for the treatment of suicidality.

A correction has been made to the Introduction section, First paragraph:

"Allopregnanolone, today best known as brexanolone and marketed as Zulresso ${ }^{\mathrm{TM}}$ for the treatment of postpartum depression is part of only two recently Food and Drug Administration (FDA)-approved fast-acting antidepressants, with esketamine nasal spray, an NMDA receptor antagonist used in treatment-resistant depression being the other (1)."

The authors apologize for this error and state that this does not change the scientific conclusions of the article in any way. The original article has been updated.

Copyright $\odot 2020$ Pinna. This is an open-access article distributed under the terms of the Creative Commons Attribution License (CC BY). The use, distribution or reproduction in other forums is permitted, provided the original author(s) and the copyright owner(s) are credited and that the original publication in this journal is cited, in accordance with accepted academic practice. No use, distribution or reproduction is permitted which does not comply with these terms. 